\title{
Sphingolipids and Lifespan Regulation
}

\author{
Xinhe Huang, Bradley R. Withers, and Robert C. Dickson \\ Department of Molecular and Cellular Biochemistry and the Lucille Markey Cancer Center, $741 \mathrm{~S}$. \\ Limestone, University of Kentucky College of Medicine, Lexington, Kentucky, 40536, USA
}

\begin{abstract}
Diseases including cancer, type 2 diabetes, cardiovascular and immune dysfunction and neurodegeneration become more prevalent as we age, and combined with the increase in average human lifespan, place an ever increasing burden on the health care system. In this chapter we focus on finding ways of modulating sphingolipids to prevent the development of age-associated diseases or delay their onset, both of which could improve health in elderly, fragile people. Reducing the incidence of or delaying the onset of diseases of aging has blossomed in the past decade because of advances in understanding signal transduction pathways and cellular processes, especially in model organisms, that are largely conserved in most eukaryotes and that can be modulated to reduce signs of aging and increase health span. In model organisms such interventions must also increase lifespan to be considered significant, but this is not a requirement for use in humans. The most encouraging interventions in model organisms involve lowering the concentration of one or more sphingolipid so as to reduce the activity of key signaling pathways, one of the most promising being the Target of Rapamycin Complex 1 (TORC1) protein kinase pathway. Other potential ways in which modulating sphingolipids may contribute to improving the health profile of the elderly is by reducing oxidative stresses, inflammatory responses and growth factor signaling. Lastly, perhaps the most interesting way to modulate sphingolipids and promote longevity is by lowering the activity of serine palmitoyltransferase, the first enzyme in the de novo sphingolipid biosynthesis pathway. Available data in yeasts and rodents are encouraging and as we gain insights into molecular mechanisms the strategies for improving human health by modulating sphingolipids will become more apparent.
\end{abstract}

\section{Keywords}

Ceramide; sphingosing-1-phosphate; myriocin; autophagy; aging

\section{Introduction}

A majority of people in developed countries will die from diseases whose prevalence increases rapidly around the sixth decade of life. These age-related diseases include cancer, cardiovascular or immune dysfunction, type 2 diabetes, obesity and various types of neurodegeneration. Studies over the past twenty years have found many roles for sphingolipids in these diseases and disease treatments based on modulating sphingolipids are

(C) 2013 Elsevier B.V. All rights reserved.

"Corresponding author at: Department of Molecular and Cellular Biochemistry, University of Kentucky College of Medicine, 741 South Limestone, BBSRB room 173, Lexington, Kentucky, 40536-0509, USA. Tel: +1 859323 6052; fax: +1 8592572283. bobd@uky.edu.

Publisher's Disclaimer: This is a PDF file of an unedited manuscript that has been accepted for publication. As a service to our customers we are providing this early version of the manuscript. The manuscript will undergo copyediting, typesetting, and review of the resulting proof before it is published in its final citable form. Please note that during the production process errors may be discovered which could affect the content, and all legal disclaimers that apply to the journal pertain. 
being sought [1-7]. Similarly, studies on other factors besides sphingolipids that are involved in age-related diseases also focus primarily on disease treatment. As an alternative to treating an advanced disease state, it may be more advantageous for improving human health to devise strategies to prevent or delay the incidence of these diseases or detect them early before they progress to an advanced stage with a low cure rate [8-10]. Hence, this review focuses on ways to modulate sphingolipids in ways that reduce the incidence of agerelated diseases or slows their progress and improves health span or the period of life spent free of these diseases and the disability they incur. In addition, such strategies may increase average or even maximal lifespan.

\section{Sphingolipid synthesis}

The overview of sphingolipid metabolism shown in Fig. 1 is a minimalistic representation of what is an extremely complex body of intracellular metabolism. Several well known sphingolipids with vital roles in humans are not shown because there is no specific link to aging and longevity. Since knowledge is constantly accumulating, readers with specific interests should examine the literature carefully for more details including other chapters in this special volume.

In eukaryotes sphingolipid synthesis begins in the endoplasmic reticulum (ER) where serine palmitoyltransferase (SPT) catalyses the condensation of serine with a fatty acyl-CoA to yield 3-ketosphinganine (ketodihydrosphingosine) (Fig. 1). The basic core of SPT is a heterodimer composed of the Lcb1 and Lcb2 subunits [11, 12]. Lcb1 and Lcb2 orthologs are present in all organisms that make sphingolipids and they are often complexed with other proteins in species-specific formats that control substrate selectivity and enzyme activity $[13,14]$.

Ketosphinganine is reduced to sphinganine (dihydrosphingosine), one of several long-chain bases, LCBs, or sphingoid bases that includes sphingosine in mammals and phytosphingosine (PHS) in yeasts and plants. Next, a fatty acid is attached to the LCB via an amide linkage in a reaction catalyzed by ceramide synthase (dihydroceramide synthase) to give dihydroceramide ( $\mathrm{N}$-acylsphinganine). In yeast a $\mathrm{C}_{26}$ fatty acid is most commonly used by ceramide synthases while mammals use a wide range of fatty acids containing 14-36 carbon atoms and sometimes having double bonds or a hydroxyl group [15, 16]. Other variations in yeast include 4-hydroxylation of the sphinganine to produce PHS which can be used also to make ceramides and hydroxylation of the fatty acids in ceramides [17]. Two yeast ceramide synthases, $\operatorname{Lag} 1$ and Lac1 $[18,19]$ will be discussed below in conjunction with lifespan. In mammals the sphinganine in dihydroceramide is desaturated to produce sphingosine with a 4,5-trans-double bond [16].

Mammals have six ceramide synthases (CerS1-CerS6), each using specific substrates and producing dihydroceramides with different fatty acid moieties to generate a large array of 'ceramides' $[12,16]$. The 'many ceramides' concept $[5,20]$ neatly summarizes the reality that ceramides are made in many cellular compartment, not just the ER, and they perform a wide range of functions including growth arrest, senescence, apoptosis and, as discussed in more detail below in Section 4, autophagy.

Ceramides are transported from the ER to the Golgi apparatus where the polar head groups are added (Fig. 1). In yeast the first complex sphingolipid to be synthesized is inositol phosphoceramide (IPC), which converted to mannose-inositol-phosphoceramide (MIPC) by transfer of mannose from GDP-mannose onto the inositol 2-OH moiety of IPC. The third and most complex sphingolipid in yeast, mannose-(inositol-P) $)_{2}$-ceramide $\left(\mathrm{M}(\mathrm{IP})_{2} \mathrm{C}\right)$, is made by attachment of a second inositol phosphate to MIPC, a reaction that requires the 
IPT1 gene [21]. Another gene, $S K N 1$, has been shown to be required for $\mathrm{M}(\mathrm{IP})_{2} \mathrm{C}$ synthesis, but its physiological roles need further characterization [22].

Ceramides in mammals are transported to the Golgi by the ceramide transfer protein (CERT) and used for sphingomyelin synthesis or they are transported by a separate, vesicle-mediated route and used to make the very large and heterogeneous group of complex sphingolipids called glycosphingolipids $[12,16,23]$.

\section{Roles for sphingolipids in modulating lifespan in model non-mammalian eukaryotes}

We want to begin with a word of caution about lifespan studies. If the level of a protein (or whatever is being manipulated) is increased or decreased and there is no effect on lifespan, then it is NOT appropriate to claim that the protein has no role in lifespan. All that can be claimed is that under the exact conditions of the experiment including strain background, nutrients and environmental conditions, there is no effect on lifespan. A claim limit is essential because under another set of conditions the protein may, in fact, have a very significant impact on lifespan. This is a very real problem because attempts to modulate human aging and lifespan are likely to only be effective in people with specific phenotypes caused by individual genetic and epigenetic variations and who live a particular lifestyle.

The first gene shown to regulate replicative lifespan (RLS) in Saccharomyces cerevisiae was termed LAG1 (Longevity-Assurance Gene 1) [24]. RLS is a measure of how many times a cell can bud to give rise to a new cell, while the other measure of yeast lifespan, chronological lifespan (CLS), is a measure of how long cells survive after they have stopped dividing and entered a quiescent or $\mathrm{G}_{\mathrm{o}}$ state [25] that yeast researchers term stationary phase [26]. Stationary phase populations contain long-lived quiescent cells that can enter the cell division cycle, and non-quiescent cells that are short-lived and cannot enter the cell division cycle, similar to the phenotype of senescent mammalian cells. Over a decade passed before $L A G 1$ was found to encode a subunit of ceramide synthase (Fig. 1) [18, 19]. While deleting LAG1 increases RLS by about fifty percent, it has no effect on CLS [27] for reasons that are unknown. Deleting $L A G 1$ in another strain background or growing cells in other culture conditions may reveal roles for Lag1 in CLS, since strain background and culture conditions can greatly influence yeast lifespan [25]. Deletion of the related $L A C 1$ gene, also encoding a component of ceramide synthase, has no influence on lifespan [28]. This suggests either that the role of Lag1 in RLS involves metabolism of specific ceramides or that it has another role not specifically related to sphingolipids, a distinct possibility since it interacts physically/ genetically with dozens of yeast proteins/genes [summarized at http:// www.yeastgenome.org/].

Another suggestion that sphingolipids regulate lifespan in S. cerevisiae comes from studies of the IPTI gene, encoding the enzyme that adds a mannosyl residue to MIPC to yield the terminal sphingolipid $\mathrm{M}(\mathrm{IP})_{2} \mathrm{C}$ (Fig. 1). Deletion of IPTI increased CLS, but only at very late times and only during severe calorie restriction (CR) in which cells were switched to water after reaching stationary phase [29]. In addition, cells were grown on a nonfermentable carbon source, unlike the conditions of a standard CLS assay where the fermentable carbon source glucose is used [25]. Growth on a non-fermentable carbon source precludes comparison to most published CLS data. Analysis of the yeast diploid single gene deletion strain set did not identify the ipt1 mutant as having a long CLS [27]. At this time it seems prudent to suggest that the role of complex sphingolipids in regulating yeast CLS needs to be examined in more detail. 
The yeast $I S C I$ gene encodes an inositol phosphosphingolipid phospholipase C, an ortholog of mammalian neutral sphingomyelinase-2, that hydrolyzes complex sphingolipids to yield ceramides and a polar head group [30]. Deletion of ISC1 shortens CLS because Isc1 has essential roles in mitochondria that are vital for longevity (e.g., oxidative phosphorylation and iron-sulphur cluster synthesis) [31]. The CLS of isdl $\Delta$ cells can, however, be greatly increased by deleting the SIT4 gene [32]. Sit4 is the catalytic subunit of a PP2A-type protein phosphatase whose activity is thought to be stimulated by ceramides [33], akin to ceramideactivated protein phosphatases in mammals [34]. These data support a model whereby ceramides produced by Isc1-mediated hydrolysis of complex sphingolipids, probably in mitochondria [35], activate Sit4. The Sit4 substrates that modulate aging remain to be identified, but some of these must be involved in mitochondrial functions including production of reactive oxygen species (ROS), since deleting SIT4 lowers ROS and improves mitochondrial energy production as part of the mechanism for enhancing CLS [31,32].

Other analyses of iscl mutant cells found an elevation in activity of the Hog1 protein kinase, a type of mitogen-activated protein kinase (MAPK) that protects cells against stresses including high osmolarity and oxidative insults [36]. Activation of Hog 1 in iscl cells, however, did not afford stress protection, rather constitutive Hog 1 activity exacerbated mitochondrial dysfunction and oxidative stress phenotypes. Hog1 is a functional homolog of the mammalian protein kinases p38 and JNK that respond to stresses, increase ceramide levels and activate ceramide-dependent signaling pathways (reviewed in [37]). Thus, it is possible that Hog 1 is also activated by a ceramide-dependent signaling pathway, but further data will be required to demonstrate this mechanism.

Overexpression of the yeast $Y D C 1$ gene, encoding a ceramidase, causes fragmentation of mitochondria and vacuoles (yeast lysosomes) and results in apoptosis and a decrease in CLS [38]. It is not known if these phenotypes are due to a reduction in ceramides or an increase in one of more of the products of ceramide hydrolysis or a combination of these two possibilities.

Ceramides have also been shown to regulate lifespan in the fruit fly Drosophila melanogaster and the roundworm Caenorhabditis elegans. Deletion of the Drosophila CERT protein (Dcert), which transfers ceramides from the ER to the Golgi, causes an increase in ROS and oxidative stress and a reduction in lifespan [39]. In contrast to these results, deletion of the alkaline ceramidase gene (Dacer), whose protein product degrades ceramides and which is orthologous to mammalian alkaline ceramidase, improves oxidative stress resistance and increases lifespan. These data imply that ceramide metabolism has a role in setting the length of a normal lifespan, but the length can be increased by lowering the concentration of ceramides [40].

The hyl-1 gene of C. elegans, highly related to the yeast LAGl gene, encodes one of three related worm ceramide synthases which each have fattyacyl chain specificity. Downregulation or inactivation of hyl-l produces a small, but statistically significant increase in lifespan $[41,42]$. These stimulating studies suggest roles for ceramides in lifespan, but it is also possible that an increase in ceramide precursors (Fig. 1) or decreases in other sphingolipids may mediate the lifespan increase. Further insight into how sphingolipids and ceramides might regulate lifespan has come from studies of worm homologs of mammalian acid sphingomyelinases $(C e A S M)$. Down-regulating the $C$. elegans ASM3 gene gave the largest increase in lifespan, but down-regulation of one of the other two CeASM genes in combination with the ASM3 increased lifespan even further [43]. The lifespan increase was shown to occur, at least in part, by decreased signaling through the insulin/growth factor-like signaling pathway (DAF-2/IIS), a major regulator of worm lifespan [44]. A model to explain these results posits that the DAF-2 receptor in the plasma membrane requires lipid rafts for 
pathway activation and down-regulating activity of one or more of the worm Asm enzymes reduces raft formation and DAF-2 signal output [43]. Ligand-dependent signaling though mammalian CD95 receptors is well known to depend on acid sphingomyelinase activity to generate a high concentration of ceramide in the outer leaflet of the plasma membrane and promote formation of lipid rafts [45]. While CD95 receptors are usually associated with apoptosis and cell death, roles in promoting growth and survival in mice are known [46]. Thus, the ASM studies in worms suggest that sphingomyelinases and ceramide-dependent lipid rafts may play more widespread roles in receptor-mediated lifespan regulation than is currently recognized [43].

We recently showed that reducing the rate of sphingolipid synthesis in S. cerevisiae increases CLS. This strategy works in several commonly used strains and under different culture conditions, indicating that it is a robust method for increasing yeast lifespan and is not dependent on a specific strain or culture conditions [47, 48]. The rate of sphingolipid synthesis was regulated by using myriocin (ISP-1) to lower SPT activity and also by using a tetracycline-repressible promoter to reduce transcription of either the $L C B 1$ or $L C B 2$ gene that encode essential subunits of SPT.

We envisioned that a reduction in the rate of sphingolipid synthesis could increase CLS by lowering the concentration of one or more sphingolipids and that this would reduce activity of the redundant Pkh1/2 protein kinases (Fig. 2A). Pkh1 and Pkh2 are orthologs of mammalian phosphoinositide-dependent protein kinase 1 (PDK1), but they are activated by sphingolipids rather than by phosphoinositides [49-51]. Pkh1/2 phosphorylate residue T570 of the Sch9 protein kinase, but this does not activate Sch9. Additional phosphorylation of Cterminal Sch9 residues by TORC1 is required for kinase activity [51]. Sch9 is the ortholog of mammalian S6 kinase (S6K) and both have roles in longevity since deletion of $\mathrm{SCH} 9$ in yeast or the S6K gene in mice increases lifespan $[52,53]$.

In these experiments a chronic, medium dose of myriocin, not an acute high dose, was used to lower but not completely inhibit SPT activity. This strategy did lower the concentration of several sphingolipids including sphinganine, phytosphingosine and IPC, but not $\mathrm{M}(\mathrm{IP})_{2} \mathrm{C}$ (Fig. 1). Lowering SPT activity in this manner produced a significant increase in CLS (Fig. 2B). Alternatively, reducing the rate of sphingolipid synthesis by using the tetracyclinerepressible $L C B 1$ gene also increased CLS (Fig. 2C), showing that the CLS increase was not due to off-target effects of myriocin. Deleting $P K H 2$ also reduced phosphorylation of Sch9 T570, as predicted, and increased CLS [47], similar to what deletion of SCH9 does in yeasts [52].

However, further studies revealed that this model was too simple and that myriocin treatment influenced signaling pathways in addition to Pkh1/2-Sch9 that had not previously been known to respond to this drug. For example, the long CLS of sch $9 \Delta$ cells could be enhanced further by myriocin treatment (Fig. 3A), indicating that myriocin controls Sch9independent processes that promote CLS extension [47].

Analysis of mRNAs in myriocin-treated and untreated cells by using microarrays revealed global transcriptional changes affecting forty percent of the yeast genome with 1252 genes up-regulated and 1497 down-regulated $(p<0.05)$ [48]. Changes included activation of the Snf1 protein kinase, the homolog of the mammalian AMP kinase (Snf1/AMPK, Fig. 2A), which controls energy homeostasis [54], along with down-regulation of the Protein Kinase A (PKA) and the TORC1 pathways (Fig. 2A). These pathways control cellular process that promote longevity including alterations in carbon metabolism and energy generation, increased respiration (oxidative phosphorylation), stress protection, autophagy and genomic stability, along with reduced ribosome assembly and translation (Fig. 2A). Perhaps the most 
notable feature of these data is that the global metabolic remodeling stimulated by myriocin treatment rivals the remodeling caused by rapamycin treatment and calorie restriction, the two most established strategies for promoting longevity [8, 55-59]. Cellular processes represented by the gene ontology (GO) terms enriched in the myriocin microarray dataset and which have known roles in CLS (Fig. 2A, brown rectangles) were verified by using targeted assays [48].

The data summarized in Fig. 2A are just a starting point for understanding all of the effects of myriocin on yeast cells that promote longevity. For example, cross-talk between signaling pathways is only understood at a rudimentary level and the degree to which each pathway and cellular process contributes to longevity is unclear. The task of assembling all of the current microarray and other published data into a network that explains how myriocin enhances lifespan will require systems biology techniques because it is impossible to manually assemble such a complex network, even one that does not attempt to decipher mechanisms at the molecular level.

So what yeast sphingolipids lowered by myriocin treatment produce the changes we observe and how do they do so? The changes in sphingolipids caused by myriocin treatment have not been analyzed extensively and the missing information including quantification of the individual species of complex sphingolipids and ceramides needs to be acquired. There are, however, several reasons why even a complete dataset of myriocin-induced changes in sphingolipids would not explain how myriocin produces global effects. First, there is very limited information about which yeast proteins interact with specific sphingolipids [60]. Second, some of the effects of the low dose, chronic myriocin treatment on CLS likely result from changes in general properties such as membrane fluidity or stress and membrane domains or compartments that may or may not produce effects on signaling pathways through specific sphingolipid-protein interactions [61-66]. A pertinent example of how such membrane properties can influence signaling is the demonstration that stress in the yeast cell wall or plasma membrane activates the Rho1 GTPase, causing it to bind TORC1 and reduce pathway activity [67]. Third, because of the interconnectedness of sphingolipid metabolism it has been very difficult to assign functions to specific yeast sphingolipids [68]. Finally, it is highly likely that changes in multiple sphingolipids are necessary to enhance yeast lifespan and identifying which sphingolipids and what they do will require new techniques and modeling strategies.

Using drug combinations to produce a synergistic improvement is common strategy in antimicrobial and cancer therapy, but this strategy has not been shown to be effective in reducing signs of aging and increasing lifespan in any organism. However, this situation seems ripe for change as we recently showed that the combination of myriocin and rapamycin can be used to produce a synergistic increase in yeast lifespan. Rapamycin is a natural product that inhibits TORC1 and is currently in hundreds of clinical trials to treat cancers and other diseases $[8,57]$. High dose rapamycin treatment or genetic impairment of TORC1 slows aging and increases lifespan in yeasts, worms, flies and mice [27, 69-73], indicating that it is likely to influence evolutionarily conserved features of aging and longevity.

To determine if a combination of myriocin and rapamycin could produce a synergistic increase in yeast CLS, we identified low concentrations of each drug that produced little or no increase in CLS and then tested various combinations. We found a wide range of concentrations that could produce a synergistic increase in CLS and data for one combination are shown in Fig. 3B[74]. Drug synergy was accessed by using three commonly used mathematical models and all verified that synergy was achieved. Targeted assays showed that the drug combination enhanced autophagy, genomic stability, 
mitochondrial functions and heat and oxidative stress resistance, emblematic features of long-lived organisms. Unexpectedly, the drug combination reduces TORC1 activity more than either individual drug, suggesting that a greater than additive, perhaps synergistic, effect is forming upstream of TORC1 to lower pathway activity. Additional data show that the drug combination induces Snf1/AMPK pathway activity and lowers PKA pathway activity, similar to what high dose myriocin treatment does (Fig. 2A). These metabolic remodeling effects of the drug combination are strikingly similar to those produced by high dose rapamycin and $\mathrm{CR}$ treatment strategies that enhance lifespan $[8,25,58,75,76]$. Besides the potential to modulate a wider array of cellular processes than any single drug and thus achieve effects that no single drug can produce, dual drug treatment also has the potential to avoid unwanted side effects that commonly occur with high doses of a single drug.

\section{Roles for sphingolipids in modulating lifespan in mammals}

Because there are no published data showing that lifespan can be increased by modulating mammalian sphingolipids, we can only speculate on whether this is possible and how it might be achieved. While the complexity of sphingolipid metabolism and number of sphingolipids in mammals is far greater than in yeasts, worms and flies, it seems likely, based on current knowledge of mammalian sphingolipid functions [2, 5, 16, 34, 77] and lifespan studies in model organisms, that modulating the concentration of ceramides or sphingosine-1-phosphate or both can be used to slow the rate of aging and enhance mammalian lifespan.

Ceramides are notable candidates for modulating aging because their concentration increases as mammals age and they are thought to play roles in age-related diseases including type 2 diabetes, cardiovascular and immune dysfunction, cancer and neurodegeneration [78-84]. The strong correlation between ceramide accumulation and increased oxidative stress and insulin resistance are intriguing as these changes are thought to promote aging and age-associated diseases [7, 85-90]. Mitochondrial decline with age is well established [see references in [91]] and links to ceramide accumulation are being established. One study found accumulation of specific ceramide species in mitochondria as rats age and linked accumulation to a decline in function of complex IV of the electron transport chain [91], consistent with increased ROS during aging. A unique feature of these studies was the finding that ceramide accumulation and impaired electron transport could be prevented by lipoic acid treatment, which prevented the age-dependent drop in mitochondrial glutathione. Maintenance of glutathione levels correlated inversely with mitochondrial neutral sphingomyelinase activity, suggesting that lipoic acid works by preventing activation of neutral sphingomyelinase and ceramide accumulation by maintaining glutathione levels. These data nicely fit with data from other model organisms, further reinforcing the idea that ceramide accumulation promotes age-associated diseases and that strategies to prevent such accumulation can potentially lower the incidence and severity of such diseases.

Recent studies in humans add to the growing literature linking ceramides to neurodegeneration [92]. In this regard, a pilot study of elderly women is revealing because it noted that low serum ceramide levels correlate with reduced risk of dementia/Alzheimer Disease [93]. This correlation is consistent with the studies mentioned above in model organisms where reducing ceramide and sphingolipid levels lowers signs of aging (e.g., stress resistance, genomic stability and autophagy increased, ROS lowered, carbon and energy metabolism remodeled) and enhances lifespan. 
Ceramides also mediate senescence of human fibroblasts and endothelial cells by mechanisms that involve impaired mitotic signaling $[94,95]$. Cellular senescence can be induced also in response to telomere shortening and ceramide signaling has been found affect telomere length in several ways (reviewed in [96]).

Roles for ceramides in longevity have been uncovered by genetic analyses. Mutations in the gene encoding ceramide synthase I (CerS1/Lass1) have been identified in flincher $(f l n)$ and toppler (to) mutant mice. These mice are characterized by neurodegenerative traits including cerebellar ataxia and Purkinje cell dysfunction and by lipofuscin accumulation, a common feature of cellular aging [97]. What appears to be a hyperactive LASS1 allele in humans has been associated with variants in the human Ras1 gene (HRAS1) and the apolipoprotein $\mathrm{E}$ gene $(A P O E)$ and this three allele combination is associated with exceptional longevity [98]. Finally, there are indications that calorie or dietary restriction decreases ceramides and other sphingolipids $[99,100]$, consistent with the idea that it ought to be possible to increase human health span and lifespan by using interventions that lower the level of pro-aging sphingolipids including ceramides. Overall, the data for ceramides are intriguing, yet they raise many questions and point to the unforeseen and multiples roles that ceramides are likely to have in lifespan.

Autophagy is now recognized as playing vital roles in aging and longevity [101] and ceramides are quickly emerging as regulators of mammalian autophagy. The Merrill laboratory initially realized that the anti-cancer drug fenretinide targets the enzyme dihydroceramide desaturase 1 that inserts the double bond into the sphinganine base of dihydroceramides to form sphingosine-containing ceramides and complex sphingolipids [77]. Thus, inhibiting this enzyme decreases normal ceramides and increases dihydroceramides which promote autophagy. The potential of inducing autophagy by lowering dihydroceramide desaturase 1 activity is being explored to treat obesity and type 2 diabetes and advances in understanding the mechanism indicate that it lowers ATP production and induces AMPK activity along with inducing autophagy [102]. Thus, modulating sphingolipids in this manner may be useful means to foster longevity.

Other studies implicate sphingolipids as mediators of autophagy, senescence and progression towards type 2 diabetes. High blood glucose leads to non-enzymatic formation of advanced glycation end products that are particularly prevalent in vascular endothelial cells and are thought to promote cardiovascular disease. Treating human endothelial cells with glycated collagen I has been shown to promote activation of sphingomyelinase activity, ceramide accumulation and clustering in the plasma membrane followed by downstream events leading to induction of autophagy. However, a pathologic response then occurs because autophagosomes fail to fuse with lysosomes, thus reducing the rate of autophagic flux and promoting entry into a senescent state [103]. These data suggest that lowering the rate of sphingolipid synthesis by long-term myriocin treatment or reducing sphingomyelinase activity or ceramide levels could lessen the damage done by type 2 diabetes and cardiovascular disease and improve human health. In fact, more recent data indicate that autophagy can be induced by modulating sphingolipids in ways that may slow age-related diseases [104-106]. Thus, these studies along with those in yeasts (Fig. 2A) suggest that autophagy is likely to be a process that can be enhanced in humans by manipulating sphingolipids in ways that slow aging and promote longevity.

Since sphingosine-1-phosphate is primarily involved in supporting growth and survival, it might contribute to aging by antagonistic pleiotropy-like effects. For example, sphingosine-1-phosphate would be essential for normal human development but in later life it might promote aging and reduce lifespan by maintaining tissues and organs in an overly 
active state that distorts the balance between sphingosine-1-phosphate and ceramide as envisioned by the 'sphingolipid rheostat' paradigm [2, 104, 107, 108].

Other sphingolipids including long-chain hexosylceramides and lactosylceramides have been implicated in aging and lifespan in mice and cultured human cells, so modulation of these could influence lifespan [100]. There also seems to be a switch in the LCBs in neuronal gangliosides from predominantly C18 to C20 during mammalian aging [109], but whether this change contributes to aging or is simply a result of aging is unknown. A recent study used lipidomic approaches to examine lipid changes in the central nervous system in methionine- restricted mice, a type of dietary restriction that increases lifespan in some organisms [99]. Changes in twenty species of sphingolipids were identified and some of these could be promoting longevity, but directed studies are needed to show such a cause and affect relationship. Other studies using global lipid analysis techniques to characterize changes in sphingolipids during aging have appeared in the recent literature and these types of studies will provide a wealth of information on which to better understand the multitude of roles that sphingolipids are sure to have in aging $[$ e.g., $[110,111]]$.

Most intriguing are studies in mammals that have used myriocin or other drugs to decrease SPT activity and treat diseases associated with aging. Studies done in different laboratories have shown that myriocin treatment reduces risk factors for metabolic syndrome and diabetes in rodent models (reviewed in $[88,112,113]$ ). Other studies using rodents have found that myriocin treatment reduces signs of cardiovascular diseases (reviewed in [85, 114]). Thus, there are reasons to think that myriocin controls evolutionarily conserved cellular functions and that these can be pharmacology modulated to reduce age-related diseases in humans.

\section{Summary}

Much of the early work on ceramides and continuing into contemporary studies revolves around their roles in mammalian stress and cell death responses (reviewed in [5, 34, 115]). Since a defining characteristic of organisms with long lifespans is enhanced stress resistance (for example, [116-118]), it is likely that modulating ceramides in humans can be used to slow aging, promote better health in the elderly, increase average lifespan and possibly increase maximal lifespan. This suggestion is supported by most of the model organism studies evaluated herein, even if this is not explicitly stated, and occurs because of the interconnectedness or ripple effects that transpire in sphingolipid metabolism [20]. For example, lowering SPT activity by myriocin treatment reduces the concentration of many sphingolipids including ceramides. Modulating other sphingolipids either in conjunction with or independently of ceramides will likely also provide a means to slow human aging and extend lifespan and the studies described here give a glimpse into how this might be accomplished.

\section{Acknowledgments}

This work was supported by grant AG024377 from the National Institutes of Health to RCD. We thank Dr. Mariana Nikolova-Karakashian for helpful comments and suggestions. We apologize to colleagues whose work we were unable to cite because of space constraints.

\section{References}

1. Rotolo J, Stancevic B, Zhang J, Hua G, Fuller J, Yin X, Haimovitz-Friedman A, Kim K, Qian M, Cardo-Vila M, Fuks Z, Pasqualini R, Arap W, Kolesnick R. Anti-ceramide antibody prevents the radiation gastrointestinal syndrome in mice. J Clin Invest. 2012; 122:1786-1790. [PubMed: 22466649] 
2. Maceyka M, Harikumar KB, Milstien S, Spiegel S. Sphingosine-1-phosphate signaling and its role in disease. Trends Cell Biol. 2012; 22:50-60. [PubMed: 22001186]

3. Hankins JL, Doshi UA, Haakenson JK, Young MM, Barth BM, Kester M. The therapeutic potential of nanoscale sphingolipid technologies. Handb Exp Pharmacol. 2013; 215:197-210. [PubMed: 23579457]

4. Morad SA, Cabot MC. Ceramide-orchestrated signalling in cancer cells. Nat Rev Cancer. 2013; 13:51-65. [PubMed: 23235911]

5. Mullen TD, Hannun YA, Obeid LM. Ceramide synthases at the centre of sphingolipid metabolism and biology. Biochem J. 2012; 441:789-802. [PubMed: 22248339]

6. Saddoughi SA, Ogretmen B. Diverse functions of ceramide in cancer cell death and proliferation. Adv Cancer Res. 2013; 117:37-58. [PubMed: 23290776]

7. Mitsutake S, Igarashi Y. Sphingolipids in lipid microdomains and obesity. Vitam Horm. 2013; 91:271-284. [PubMed: 23374721]

8. Blagosklonny MV. Prospective treatment of age-related diseases by slowing down aging. Am J Pathol. 2012; 181:1142-1146. [PubMed: 22841821]

9. Newgard CB, Sharpless NE. Coming of age: molecular drivers of aging and therapeutic opportunities. J Clin Invest. 2013; 123:946-950. [PubMed: 23454756]

10. Vogelstein B, Papadopoulos N, Velculescu VE, Zhou S, Diaz LA Jr, Kinzler KW. Cancer genome landscapes. Science. 2013; 339:1546-1558. [PubMed: 23539594]

11. Hanada K. Serine palmitoyltransferase, a key enzyme of sphingolipid metabolism. Biochim Biophys Acta. 2003; 1632:16-30. [PubMed: 12782147]

12. Tidhar R, Futerman AH. The complexity of sphingolipid biosynthesis in the endoplasmic reticulum. Biochim Biophys Acta. 2013; 1833:2511-2518. [PubMed: 23611790]

13. Breslow DK, Weissman JS. Membranes in balance: mechanisms of sphingolipid homeostasis. Mol Cell. 2010; 40:267-279. [PubMed: 20965421]

14. Lowther J, Naismith JH, Dunn TM, Campopiano DJ. Structural, mechanistic and regulatory studies of serine palmitoyltransferase. Biochem Soc Trans. 2012; 40:547-554. [PubMed: 22616865]

15. Dickson RC, Lester RL. Metabolism and selected functions of sphingolipids in the yeast Saccharomyces cerevisiae. Biochim Biophys Acta. 1999; 1438:305-321. [PubMed: 10366774]

16. Merrill AH Jr. Sphingolipid and glycosphingolipid metabolic pathways in the era of sphingolipidomics. Chem Rev. 2011; 111:6387-6422. [PubMed: 21942574]

17. Dickson RC, Lester RL. Sphingolipid functions in Saccharomyces cerevisiae. Biochim Biophys Acta. 2002; 1583:13-25. [PubMed: 12069845]

18. Guillas I, Kirchman PA, Chuard R, Pfefferli M, Jiang JC, Jazwinski SM, Conzelmann A. C26CoA-dependent ceramide synthesis of Saccharomyces cerevisiae is operated by Lag1p and Lac1p. EBMO J. 2001; 20:2655-2665.

19. Schorling S, Vallee B, Barz WP, Riezman H, Oesterhelt D. Lag1p and Lac1p Are Essential for the Acyl-CoA-dependent Ceramide Synthase Reaction in Saccharomyces cerevisae. Mol Biol Cell. 2001; 12:3417-3427. [PubMed: 11694577]

20. Hannun YA, Obeid LM. Many ceramides. J Biol Chem. 2011; 286:27855-27862. [PubMed: 21693702]

21. Dickson RC, Nagiec EE, Wells GB, Nagiec MM, Lester RL. Synthesis of mannose-(inositol-P)2ceramide, the major sphingolipid in Saccharomyces cerevisiae, requires the IPT1(YDR072c) gene. J Biol Chem. 1997; 272:29620-29625. [PubMed: 9368028]

22. Thevissen K, Idkowiak-Baldys J, Im YJ, Takemoto J, Francois IE, Ferket KK, Aerts AM, Meert EM, Winderickx J, Roosen J, Cammue BP. SKN1, a novel plant defensin-sensitivity gene in Saccharomyces cerevisiae, is implicated in sphingolipid biosynthesis. FEBS Lett. 2005; 579:1973-1977. [PubMed: 15792805]

23. Hanada K. Intracellular trafficking of ceramide by ceramide transfer protein. Proc Jpn Acad Ser B Phys Biol Sci. 2010; 86:426-437.

24. D'Mello N P, Childress AM, Franklin DS, Kale SP, Pinswasdi C, Jazwinski SM. Cloning and characterization of LAG1, a longevity-assurance gene in yeast. J Biol Chem. 1994; 269:1545115459. [PubMed: 8195187] 
25. Longo VD, Shadel GS, Kaeberlein M, Kennedy B. Replicative and Chronological Aging in Saccharomyces cerevisiae. Cell Metab. 2012; 16:18-31. [PubMed: 22768836]

26. Werner-Washburne M, Roy S, Davidson GS. Aging and the Survival of Quiescent and Nonquiescent Cells in Yeast Stationary-Phase Cultures. Subcell Biochem. 2012; 57:123-143. [PubMed: 22094420]

27. Powers RW 3rd, Kaeberlein M, Caldwell SD, Kennedy BK, Fields S. Extension of chronological life span in yeast by decreased TOR pathway signaling. Genes Dev. 2006; 20:174-184. [PubMed: 16418483]

28. Jiang JC, Kirchman PA, Allen M, Jazwinski SM. Suppressor analysis points to the subtle role of the LAG1 ceramide synthase gene in determining yeast longevity. Exp Gerontol. 2004; 39:999_ 1009. [PubMed: 15236759]

29. Aerts AM, Francois IE, Bammens L, Cammue BP, Smets B, Winderickx J, Accardo S, De Vos DE, Thevissen K. Level of M(IP)2C sphingolipid affects plant defensin sensitivity, oxidative stress resistance and chronological life-span in yeast. FEBS Lett. 2006; 580:1903-1907. [PubMed: 16527275]

30. Sawai H, Okamoto Y, Luberto C, Mao C, Bielawska A, Domae N, Hannun YA. Identification of ISC1 (YER019w) as inositol phosphosphingolipid phospholipase C in Saccharomyces cerevisiae. J Biol Chem. 2000; 275:39793-39798. [PubMed: 11006294]

31. Almeida T, Marques M, Mojzita D, Amorim MA, Silva RD, Almeida B, Rodrigues P, Ludovico P, Hohmann S, Moradas-Ferreira P, Corte-Real M, Costa V. Isc1p Plays a Key Role in Hydrogen Peroxide Resistance and Chronological Lifespan through Modulation of Iron Levels and Apoptosis. Mol Biol Cell. 2008; 19:865-876. [PubMed: 18162582]

32. Barbosa AD, Osorio H, Sims KJ, Almeida T, Alves M, Bielawski J, Amorim MA, MoradasFerreira P, Hannun YA, Costa V. Role for Sit4p-dependent mitochondrial dysfunction in mediating the shortened chronological lifespan and oxidative stress sensitivity of Isc1p-deficient cells. Mol Microbiol. 2011; 81:515-527. [PubMed: 21707788]

33. Nickels JT, Broach JR. A ceramide-activated protein phosphatase mediates ceramide-induced G1 arrest of Saccharomyces cerevisiae. Genes Dev. 1996; 10:382-394. [PubMed: 8600023]

34. Hannun YA, Obeid LM. Principles of bioactive lipid signalling: lessons from sphingolipids. Nat Rev Mol Cell Biol. 2008; 9:139-150. [PubMed: 18216770]

35. de Avalos SV, Okamoto Y, Hannun YA. Activation and localization of inositol phosphosphingolipid phospholipase $\mathrm{C}$, Isc1p, to the mitochondria during growth of Saccharomyces cerevisiae. J Biol Chem. 2004; 279:11537-11545. [PubMed: 14699160]

36. Barbosa AD, Graca J, Mendes V, Chaves SR, Amorim MA, Mendes MV, Moradas-Ferreira P, Corte-Real M, Costa V. Activation of the Hog1p kinase in Isc1p-deficient yeast cells is associated with mitochondrial dysfunction, oxidative stress sensitivity and premature aging. Mech Ageing Dev. 2012; 133:317-330. [PubMed: 22445853]

37. Mathias S, Pena LA, Kolesnick RN. Signal transduction of stress via ceramide. Biochem J. 1998; 335:465-480. [PubMed: 9794783]

38. Aerts AM, Zabrocki P, Francois IE, Carmona-Gutierrez D, Govaert G, Mao C, Smets B, Madeo F, Winderickx J, Cammue BP, Thevissen K. Ydc1p ceramidase triggers organelle fragmentation, apoptosis and accelerated ageing in yeast. Cell Mol Life Sci. 2008; 65:1933-1942. [PubMed: 18500447]

39. Rao RP, Yuan C, Allegood JC, Rawat SS, Edwards MB, Wang X, Merrill AH Jr, Acharya U, Acharya JK. Ceramide transfer protein function is essential for normal oxidative stress response and lifespan. Proc Natl Acad Sci U S A. 2007; 104:11364-11369. [PubMed: 17592126]

40. Yang Q, Gong ZJ, Zhou Y, Yuan JQ, Cheng J, Tian L, Li S, Lin XD, Xu R, Zhu ZR, Mao C. Role of Drosophila alkaline ceramidase (Dacer) in Drosophila development and longevity. Cell Mol Life Sci. 2010; 67:1477-1490. [PubMed: 20112046]

41. Tedesco P, Jiang J, Wang J, Jazwinski SM, Johnson TE. Genetic analysis of hyl-1, the C. elegans homolog of LAG1/LASS1. Age (Dordr). 2008; 30:43-52. [PubMed: 19424872]

42. Menuz V, Howell KS, Gentina S, Epstein S, Riezman I, Fornallaz-Mulhauser M, Hengartner MO, Gomez M, Riezman H, Martinou JC. Protection of C. elegans from anoxia by HYL-2 ceramide synthase. Science. 2009; 324:381-384. [PubMed: 19372430] 
43. Kim Y, Sun H. ASM-3 acid sphingomyelinase functions as a positive regulator of the DAF-2/ AGE-1 signaling pathway and serves as a novel anti-aging target. PLoS One. 2012; 7:e45890. [PubMed: 23049887]

44. Kenyon CJ. The genetics of ageing. Nature. 2010; 464:504-512. [PubMed: 20336132]

45. Grassme H, Jekle A, Riehle A, Schwarz H, Berger J, Sandhoff K, Kolesnick R, Gulbins E. CD95 signaling via ceramide-rich membrane rafts. J Biol Chem. 2001; 276:20589-20596. [PubMed: 11279185]

46. Chen L, Park SM, Tumanov AV, Hau A, Sawada K, Feig C, Turner JR, Fu YX, Romero IL, Lengyel E, Peter ME. CD95 promotes tumour growth. Nature. 2010; 465:492-496. [PubMed: 20505730]

47. Huang X, Liu J, Dickson RC. Down-regulating sphingolipid synthesis increases yeast lifespan. PLoS Genet. 2012; 8:e1002493. [PubMed: 22319457]

48. Liu J, Huang X, Withers BR, Blalock E, Liu K, Dickson RC. Reducing Sphingolipid Synthesis Orchestrates Global Changes to Extend Yeast Lifespan. Aging Cell. 2013; 12 in press.

49. Roelants FM, Torrance PD, Thorner J. Differential roles of PDK1- and PDK2- phosphorylation sites in the yeast AGC kinases Ypk1, Pkc1 and Sch9. Microbiol. 2004; 150:3289-3304.

50. Liu K, Zhang X, Lester RL, Dickson RC. The sphingoid long chain base phytosphingosine activates AGC-type protein kinases in Saccharomyces cerevisiae including Ypk1, Ypk2, and Sch9. J Biol Chem. 2005; 280:22679-22987. [PubMed: 15840588]

51. Urban J, Soulard A, Huber A, Lippman S, Mukhopadhyay D, Deloche O, Wanke V, Anrather D, Ammerer G, Riezman H, Broach JR, De Virgilio C, Hall MN, Loewith R. Sch9 is a major target of TORC1 in Saccharomyces cerevisiae. Mol Cell. 2007; 26:663-674. [PubMed: 17560372]

52. Fabrizio P, Pozza F, Pletcher SD, Gendron CM, Longo VD. Regulation of longevity and stress resistance by Sch9 in yeast. Science. 2001; 292:288-290. [PubMed: 11292860]

53. Selman C, Tullet JM, Wieser D, Irvine E, Lingard SJ, Choudhury AI, Claret M, Al-Qassab H, Carmignac D, Ramadani F, Woods A, Robinson IC, Schuster E, Batterham RL, Kozma SC, Thomas G, Carling D, Okkenhaug K, Thornton JM, Partridge L, Gems D, Withers DJ. Ribosomal protein S6 kinase 1 signaling regulates mammalian life span. Science. 2009; 326:140-144. [PubMed: 19797661]

54. Hardie DG, Ross FA, Hawley SA. AMPK: a nutrient and energy sensor that maintains energy homeostasis. Nat Rev Mol Cell Biol. 2012; 13:251-262. [PubMed: 22436748]

55. Niccoli T, Partridge L. Ageing as a risk factor for disease. Curr Biol. 2012; 22:R741-752. [PubMed: 22975005]

56. Kaeberlein M. Longevity and aging. F1000Prime Rep. 2013; 5:5. [PubMed: 23513177]

57. Cornu M, Albert V, Hall MN. mTOR in aging, metabolism, and cancer. Curr Opin Genet Dev. 2013; 23:53-62. [PubMed: 23317514]

58. Anderson RM, Weindruch R. The caloric restriction paradigm: implications for healthy human aging. Am J Hum Biol. 2012; 24:101-106. [PubMed: 22290875]

59. Barzilai N, Huffman DM, Muzumdar RH, Bartke A. The critical role of metabolic pathways in aging. Diabetes. 2012; 61:1315-1322. [PubMed: 22618766]

60. Gallego O, Betts MJ, Gvozdenovic-Jeremic J, Maeda K, Matetzki C, Aguilar- Gurrieri C, BeltranAlvarez P, Bonn S, Fernandez-Tornero C, Jensen LJ, Kuhn M, Trott J, Rybin V, Muller CW, Bork P, Kaksonen M, Russell RB, Gavin AC. A systematic screen for protein-lipid interactions in Saccharomyces cerevisiae. Mol Syst Biol. 2010; 6:430. [PubMed: 21119626]

61. Klose C, Ejsing CS, Garcia-Saez AJ, Kaiser HJ, Sampaio JL, Surma MA, Shevchenko A, Schwille P, Simons K. Yeast lipids can phase-separate into micrometer-scale membrane domains. J Biol Chem. 2010; 285:30224-30232. [PubMed: 20647309]

62. Hyman AA, Simons K. Cell biology. Beyond oil and water--phase transitions in cells. Science. 2012; 337:1047-1049. [PubMed: 22936764]

63. Santos AX, Riezman H. Yeast as a model system for studying lipid homeostasis and function. FEBS Lett. 2012; 586:2858-2867. [PubMed: 22824640]

64. Berchtold D, Piccolis M, Chiaruttini N, Riezman I, Riezman H, Roux A, Walther TC, Loewith R. Plasma membrane stress induces relocalization of Slm proteins and activation of TORC2 to promote sphingolipid synthesis. Nat Cell Biol. 2012; 14:542-547. [PubMed: 22504275] 
65. Babu M, Vlasblom J, Pu S, Guo X, Graham C, Bean BD, Burston HE, Vizeacoumar FJ, Snider J, Phanse S, Fong V, Tam YY, Davey M, Hnatshak O, Bajaj N, Chandran S, Punna T, Christopolous C, Wong V, Yu A, Zhong G, Li J, Stagljar I, Conibear E, Wodak SJ, Emili A, Greenblatt JF. Interaction landscape of membrane-protein complexes in Saccharomyces cerevisiae. Nature. 2012; 489:585-589. [PubMed: 22940862]

66. Douglas LM, Wang HX, Li L, Konopka JB. Membrane Compartment Occupied by Can1 (MCC) and Eisosome Subdomains of the Fungal Plasma Membrane. Membranes (Basel). 2011; 1:394411. [PubMed: 22368779]

67. Yan G, Lai Y, Jiang Y. The TOR complex 1 is a direct target of Rho1 GTPase. Mol Cell. 2012; 45:743-753. [PubMed: 22445487]

68. Cowart LA, Shotwell M, Worley ML, Richards AJ, Montefusco DJ, Hannun YA, Lu X. Revealing a signaling role of phytosphingosine-1-phosphate in yeast. Mol Syst Biol. 2010; 6:349. [PubMed: 20160710]

69. Vellai T, Takacs-Vellai K, Zhang Y, Kovacs AL, Orosz L, Muller F. Genetics: influence of TOR kinase on lifespan in C. elegans. Nature. 2003; 426:620. [PubMed: 14668850]

70. Jia K, Chen D, Riddle DL. The TOR pathway interacts with the insulin signaling pathway to regulate C. elegans larval development. metabolism and life span, Development. 2004; 131:38973906.

71. Bjedov I, Toivonen JM, Kerr F, Slack C, Jacobson J, Foley A, Partridge L. Mechanisms of life span extension by rapamycin in the fruit fly Drosophila melanogaster. Cell Metab. 2010; 11:3546. [PubMed: 20074526]

72. Harrison DE, Strong R, Sharp ZD, Nelson JF, Astle CM, Flurkey K, Nadon NL, Wilkinson JE, Frenkel K, Carter CS, Pahor M, Javors MA, Fernandez E, Miller RA. Rapamycin fed late in life extends lifespan in genetically heterogeneous mice. Nature. 2009; 460:392-395. [PubMed: 19587680]

73. Wilkinson JE, Burmeister L, Brooks SV, Chan CC, Friedline S, Harrison DE, Hejtmancik JF, Nadon N, Strong R, Wood LK, Woodward MA, Miller RA. Rapamycin slows aging in mice. Aging Cell. 2012; 11:675-682. [PubMed: 22587563]

74. Huang X, Liu J, Withers BR, Samide AJ, Leggas M, Dickson RC. Reducing signs of aging and increasing lifespan by drug synergy. Aging Cell. 2013; 12:652-660. [PubMed: 23601176]

75. Bjedov I, Partridge L. A longer and healthier life with TOR down-regulation: genetics and drugs. Biochem Soc Trans. 2011; 39:460-465. [PubMed: 21428920]

76. Wuttke D, Connor R, Vora C, Craig T, Li Y, Wood S, Vasieva O, Shmookler Reis R, Tang F, de Magalhaes JP. Dissecting the gene network of dietary restriction to identify evolutionarily conserved pathways and new functional genes. PLoS Genet. 2012; 8:e1002834. [PubMed: 22912585]

77. Zheng W, Kollmeyer J, Symolon H, Momin A, Munter E, Wang E, Kelly S, Allegood JC, Liu Y, Peng Q, Ramaraju H, Sullards MC, Cabot M, Merrill AH Jr. Ceramides and other bioactive sphingolipid backbones in health and disease: lipidomic analysis, metabolism and roles in membrane structure, dynamics, signaling and autophagy. Biochim Biophys Acta. 2006; 1758:1864-1884. [PubMed: 17052686]

78. Cutler RG, Mattson MP. Sphingomyelin and ceramide as regulators of development and lifespan. Mech Ageing Dev. 2001; 122:895-908. [PubMed: 11348657]

79. Nikolova-Karakashian M, Karakashian A, Rutkute K. Role of neutral sphingomyelinases in aging and inflammation. Subcell Biochem. 2008; 49:469-486. [PubMed: 18751923]

80. Sacket SJ, Chung HY, Okajima F, Im DS. Increase in sphingolipid catabolic enzyme activity during aging. Acta Pharmacol Sin. 2009; 30:1454-1461. [PubMed: 19749786]

81. Jana A, Hogan EL, Pahan K. Ceramide and neurodegeneration: susceptibility of neurons and oligodendrocytes to cell damage and death. J Neurol Sci. 2009; 278:5-15. [PubMed: 19147160]

82. Guenther GG, Edinger AL. A new take on ceramide: starving cells by cutting off the nutrient supply. Cell Cycle. 2009; 8:1122-1126. [PubMed: 19282666]

83. Ohno-Iwashita Y, Shimada Y, Hayashi M, Inomata M. Plasma membrane microdomains in aging and disease. Geriatr Gerontol Int. 2010; 10(1):S41-52. [PubMed: 20590841] 
84. Webb LM, Arnholt AT, Venable ME. Phospholipase D modulation by ceramide in senescence. Mol Cell Biochem. 2010; 337:153-158. [PubMed: 19856145]

85. Jiang XC, Goldberg IJ, Park TS. Sphingolipids and cardiovascular diseases: lipoprotein metabolism, atherosclerosis and cardiomyopathy. Adv Exp Med Biol. 2011; 721:19-39. [PubMed: 21910080]

86. Vandanmagsar B, Youm YH, Ravussin A, Galgani JE, Stadler K, Mynatt RL, Ravussin E, Stephens JM, Dixit VD. The NLRP3 inflammasome instigates obesity-induced inflammation and insulin resistance. Nat Med. 2011; 17:179-188. [PubMed: 21217695]

87. Nikolova-Karakashian MN, Reid MB. Sphingolipid metabolism, oxidant signaling, and contractile function of skeletal muscle. Antioxid Redox Signal. 2011; 15:2501-2517. [PubMed: 21453197]

88. Chavez JA, Summers SA. A ceramide-centric view of insulin resistance. Cell Metab. 2012; 15:585-594. [PubMed: 22560211]

89. de la Monte SM. Triangulated mal-signaling in Alzheimer's disease: roles of neurotoxic ceramides, ER stress, and insulin resistance reviewed. J Alzheimers Dis. 2012; 30(2):S231-249. [PubMed: 22337830]

90. Bikman BT. A role for sphingolipids in the pathophysiology of obesity-induced inflammation. Cell Mol Life Sci. 2012; 69:2135-2146. [PubMed: 22294100]

91. Monette JS, Gomez LA, Moreau RF, Dunn KC, Butler JA, Finlay LA, Michels AJ, Shay KP, Smith EJ, Hagen TM. (R)-alpha-Lipoic acid treatment restores ceramide balance in aging rat cardiac mitochondria. Pharmacol Res. 2011; 63:23-29. [PubMed: 20934512]

92. van Echten-Deckert G, Walter J. Sphingolipids: critical players in Alzheimer's disease. Prog Lipid Res. 2012; 51:378-393. [PubMed: 22835784]

93. Mielke MM, Bandaru VV, Haughey NJ, Xia J, Fried LP, Yasar S, Albert M, Varma V, Harris G, Schneider EB, Rabins PV, Bandeen-Roche K, Lyketsos CG, Carlson MC. Serum ceramides increase the risk of Alzheimer disease: the Women's Health and Aging Study II. Neurology. 2012; 79:633-641. [PubMed: 22815558]

94. Venable ME, Yin X. Ceramide induces endothelial cell senescence. Cell Biochem Funct. 2009; 27:547-551. [PubMed: 19842094]

95. Venable ME, Lee JY, Smyth MJ, Bielawska A, Obeid LM. Role of ceramide in cellular senescence. J Biol Chem. 1995; 270:30701-30708. [PubMed: 8530509]

96. Saddoughi SA, Song P, Ogretmen B. Roles of bioactive sphingolipids in cancer biology and therapeutics. Subcell Biochem. 2008; 49:413-440. [PubMed: 18751921]

97. Zhao L, Spassieva SD, Jucius TJ, Shultz LD, Shick HE, Macklin WB, Hannun YA, Obeid LM, Ackerman SL. A deficiency of ceramide biosynthesis causes cerebellar purkinje cell neurodegeneration and lipofuscin accumulation. PLoS Genet. 2011; 7:e1002063. [PubMed: 21625621]

98. Jazwinski SM, Kim S, Dai J, Li L, Bi X, Jiang JC, Arnold J, Batzer MA, Walker JA, Welsh DA, Lefante CM, Volaufova J, Myers L, Su LJ, Hausman DB, Miceli MV, Ravussin E, Poon LW, Cherry KE, Welsch MA. HRAS1 and LASS1 with APOE are associated with human longevity and healthy aging. Aging Cell. 2010; 9:698-708. [PubMed: 20569235]

99. Jove M, Ayala V, Ramirez-Nunez O, Naudi A, Cabre R, Spickett CM, Portero-Otin M, Pamplona R. Specific Lipidome Signatures in Central Nervous System from Methionine-Restricted Mice. J Proteome Res. 2013; 12:2678-2689.

100. Hernandez-Corbacho MJ, Jenkins RW, Clarke CJ, Hannun YA, Obeid LM, Snider AJ, Siskind LJ. Accumulation of Long-Chain Glycosphingolipids during Aging Is Prevented by Caloric Restriction. PLoS One. 2011; 6:e20411. [PubMed: 21687659]

101. Rubinsztein DC, Marino G, Kroemer G. Autophagy and aging. Cell. 2011; 146:682-695. [PubMed: 21884931]

102. Sentelle RD, Senkal CE, Jiang W, Ponnusamy S, Gencer S, Selvam SP, Ramshesh VK, Peterson YK, Lemasters JJ, Szulc ZM, Bielawski J, Ogretmen B. Ceramide targets autophagosomes to mitochondria and induces lethal mitophagy. Nat Chem Biol. 2012; 8:831-838. [PubMed: 22922758] 
103. Patschan S, Chen J, Polotskaia A, Mendelev N, Cheng J, Patschan D, Goligorsky MS. Lipid mediators of autophagy in stress-induced premature senescence of endothelial cells. Am J Physiol Heart Circ Physiol. 2008; 294:H1119-1129. [PubMed: 18203850]

104. Taniguchi M, Kitatani K, Kondo T, Hashimoto-Nishimura M, Asano S, Hayashi A, Mitsutake S, Igarashi Y, Umehara H, Takeya H, Kigawa J, Okazaki T. Regulation of autophagy and its associated cell death by "sphingolipid rheostat": reciprocal role of ceramide and sphingosine 1phosphate in the mammalian target of rapamycin pathway. J Biol Chem. 2012; 287:3989839910. [PubMed: 23035115]

105. Jiang W, Ogretmen B. Ceramide stress in survival versus lethal autophagy paradox: ceramide targets autophagosomes to mitochondria and induces lethal mitophagy. Autophagy. 2013; 9:258259. [PubMed: 23182807]

106. Young MM, Kester M, Wang HG. Sphingolipids: regulators of crosstalk between apoptosis and autophagy. J Lipid Res. 2013; 54:5-19. [PubMed: 23152582]

107. Loh KC, Baldwin D, Saba JD. Sphingolipid signaling and hematopoietic malignancies: to the rheostat and beyond. Anticancer Agents Med Chem. 2011; 11:782-793. [PubMed: 21707493]

108. Van Brocklyn JR, Williams JB. The control of the balance between ceramide and sphingosine-1phosphate by sphingosine kinase: oxidative stress and the seesaw of cell survival and death. Comp Biochem Physiol B Biochem Mol Biol. 2012; 163:26-36. [PubMed: 22613819]

109. Sonnino S, Chigorno V. Ganglioside molecular species containing C18- and C20-sphingosine in mammalian nervous tissues and neuronal cell cultures. Biochim Biophys Acta. 2000; 1469:6377. [PubMed: 10998569]

110. Collino S, Montoliu I, Martin FP, Scherer M, Mari D, Salvioli S, Bucci L, Ostan R, Monti D, Biagi E, Brigidi P, Franceschi C, Rezzi S. Metabolic signatures of extreme longevity in northern italian centenarians reveal a complex remodeling of lipids, amino acids, and gut microbiota metabolism. PLoS One. 2013; 8:e56564. [PubMed: 23483888]

111. Molano A, Huang Z, Marko MG, Azzi A, Wu D, Wang E, Kelly SL, Merrill AH Jr, Bunnell SC, Meydani SN. Age-dependent changes in the sphingolipid composition of mouse CD4+ T cell membranes and immune synapses implicate glucosylceramides in age-related $\mathrm{T}$ cell dysfunction. PLoS One. 2012; 7:e47650. [PubMed: 23110086]

112. Ussher JR, Folmes CD, Keung W, Fillmore N, Jaswal JS, Cadete VJ, Beker DL, Lam VH, Zhang L, Lopaschuk GD. Inhibition of serine palmitoyl transferase I reduces cardiac ceramide levels and increases glycolysis rates following diet-induced insulin resistance. PLoS One. 2012; 7:e37703. [PubMed: 22629445]

113. Dekker MJ, Baker C, Naples M, Samsoondar J, Zhang R, Qiu W, Sacco J, Adeli K. Inhibition of sphingolipid synthesis improves dyslipidemia in the diet-induced hamster model of insulin resistance: Evidence for the role of sphingosine and sphinganine in hepatic VLDL-apoB100 overproduction. Atherosclerosis. 2013; 228:98-109. [PubMed: 23466071]

114. Glaros EN, Kim WS, Garner B. Myriocin-mediated up-regulation of hepatocyte apoA-I synthesis is associated with ERK inhibition. Clin Sci (Lond). 2010; 118:727-736. [PubMed: 20102334]

115. Morales A, Lee H, Goni FM, Kolesnick R, Fernandez-Checa JC. Sphingolipids and cell death. Apoptosis. 2007; 12:923-939. [PubMed: 17294080]

116. Fabrizio P, Longo VD. The chronological life span of Saccharomyces cerevisiae. Aging Cell. 2003; 2:73-81. [PubMed: 12882320]

117. Gems D, Partridge L. Stress-response hormesis and aging: "that which does not kill us makes us stronger”. Cell Metab. 2008; 7:200-203. [PubMed: 18316025]

118. Haigis MC, Yankner BA. The aging stress response. Mol Cell. 2010; 40:333-344. [PubMed: 20965426]

119. Dickson RC. Roles for sphingolipids in Saccharomyces cerevisiae. Adv Exp Med Biol. 2010; 688:217-231. [PubMed: 20919657]

120. De Virgilio C. The essence of yeast quiescence. FEMS Microbiol Rev. 2012; 36:306-339. [PubMed: 21658086] 


\section{Abbreviations}

$\begin{array}{ll}\text { CLS } & \text { chronological lifespan } \\ \text { CR } & \text { calorie restriction } \\ \text { CS } & \text { ceramide synthase } \\ \text { DHS } & \text { dihydrosphingosine } \\ \text { LCB } & \text { long-chain base } \\ \text { LCBP } & \text { long-chain base phosphate } \\ \text { PHS } & \text { phytosphingosine } \\ \text { SPT } & \text { serine palmitoyltransferase }\end{array}$




\section{Highlights}

- Modulation of Sphingolipids Extends Lifespan in Yeasts and Flies

- Ceramides and other Sphingolipids Regulate Autophagy

- Combination Treatments Produce a Synergistic Extension of Lifespan

- Modulating Sphingolipids to Reduce the Incidence and Onset of Age-associated Diseases 


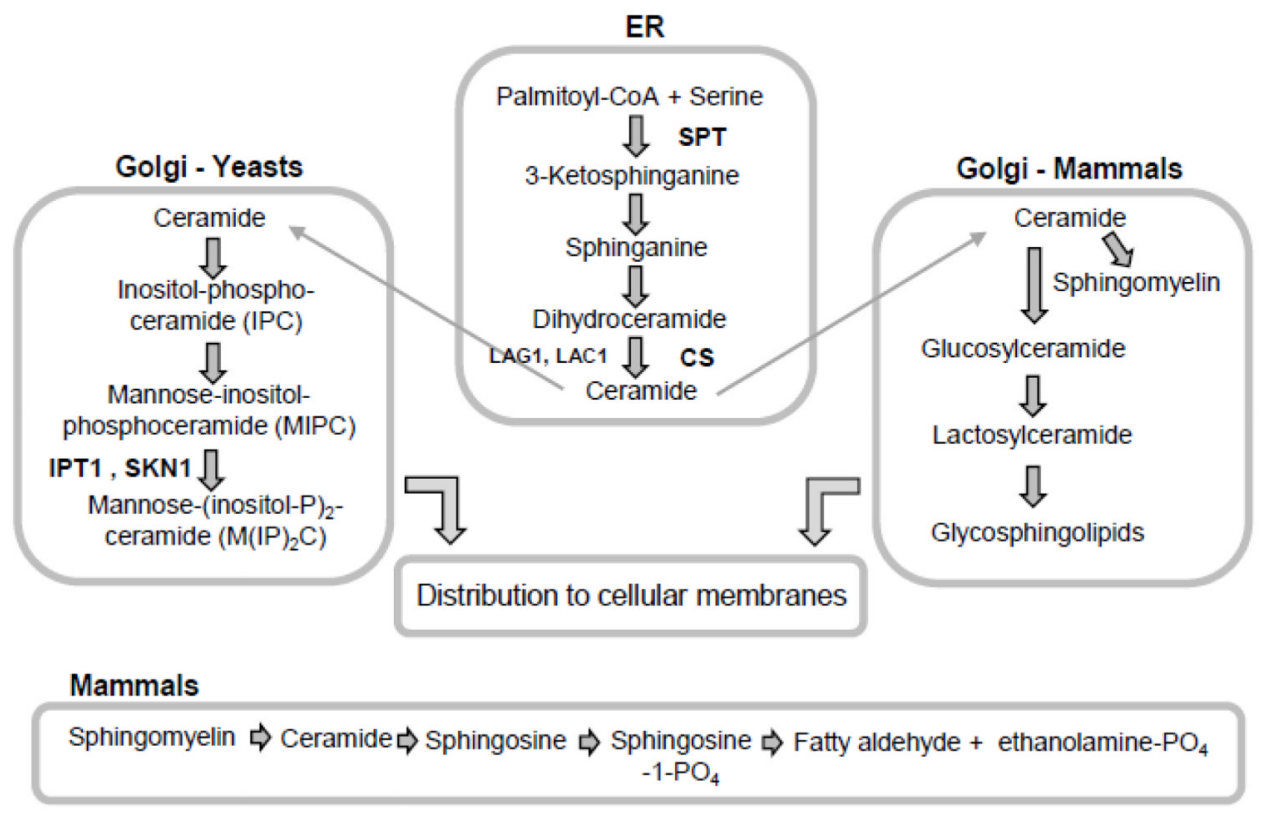

Fig. 1.

Outline of sphingolipid metabolism. This diagram presents a simplified view of sphingolipid metabolism and more detailed information is available in the literature [12, 13, 16, 34, 119]. Initial steps in sphingolipid synthesis occur in the ER in all eukaryotes that make sphingolipids. Later steps in the synthesis of complex sphingolipids in the Golgi apparatus and that are specific to yeast (Saccharomyces cerevisiae) or mammals are indicated. Shown at the bottom of the figure is one way to generate ceramides and then convert it to sphingosine-1- $\mathrm{PO}_{4}$. 

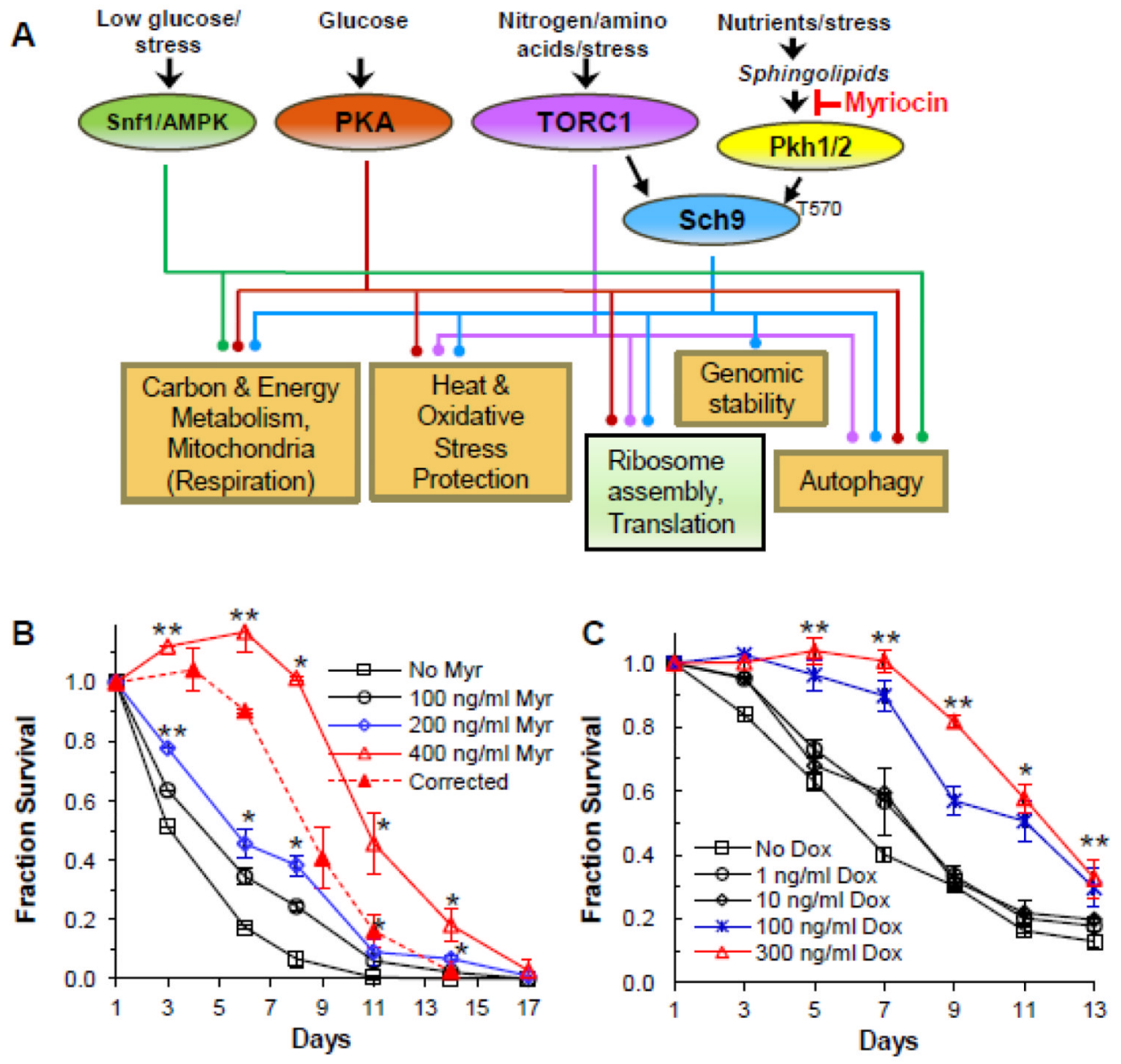

Fig. 2.

Decreasing the rate of yeast sphingolipid synthesis increases lifespan. A. This diagram summarizes known links between inducers (nutrients and stresses), protein kinases and signaling pathways, and cellular processes modulated by myriocin treatment that have known roles in CLS. The cellular processes are based upon GO terms enriched in the myriocin-responsive gene set and which were verified by targeted experiments [48]. Activation, inhibition and repression are not indicated in order to emphasize linkage relationships. Details about signaling pathways can be found in a review [120]. The brownshaded rectangles indicate up- regulated processes and green-shaded boxes indicate downregulated processes (Figure adapted from) [48]. B. CLS of DBY746 cells treated myriocin $(400 \mathrm{ng} / \mathrm{ml})$ to reduce the rate of sphingolipid synthesis. Data represent the mean \pm SEM of surviving cells (* $\mathrm{p}<0.05$, ** $\mathrm{p}<0.01$, No Myr vs 200 and $400 \mathrm{ng} / \mathrm{ml}$ Myr). To compensate for the slow growth and extended growth phase of cells treated with $400 \mathrm{ng} / \mathrm{ml}$ of myriocin (solid red line), the viability at the $120 \mathrm{hr}$ time point, CLS day 3, was set as CLS day 1 (dashed red line). C. CLS of tetO7-LCB1 cells treated or not treated with doxycycline (100 $\mathrm{ng} / \mathrm{ml}$ ) to reduce gene expression and lower the rate of sphingolipid synthesis. Data show the mean \pm SEM of surviving cells $(* \mathrm{p}<0.05, * * \mathrm{p}<0.01$, No Dox vs doxycycline). Panels B and $\mathrm{C}$ are reproduced with permission [47]. 

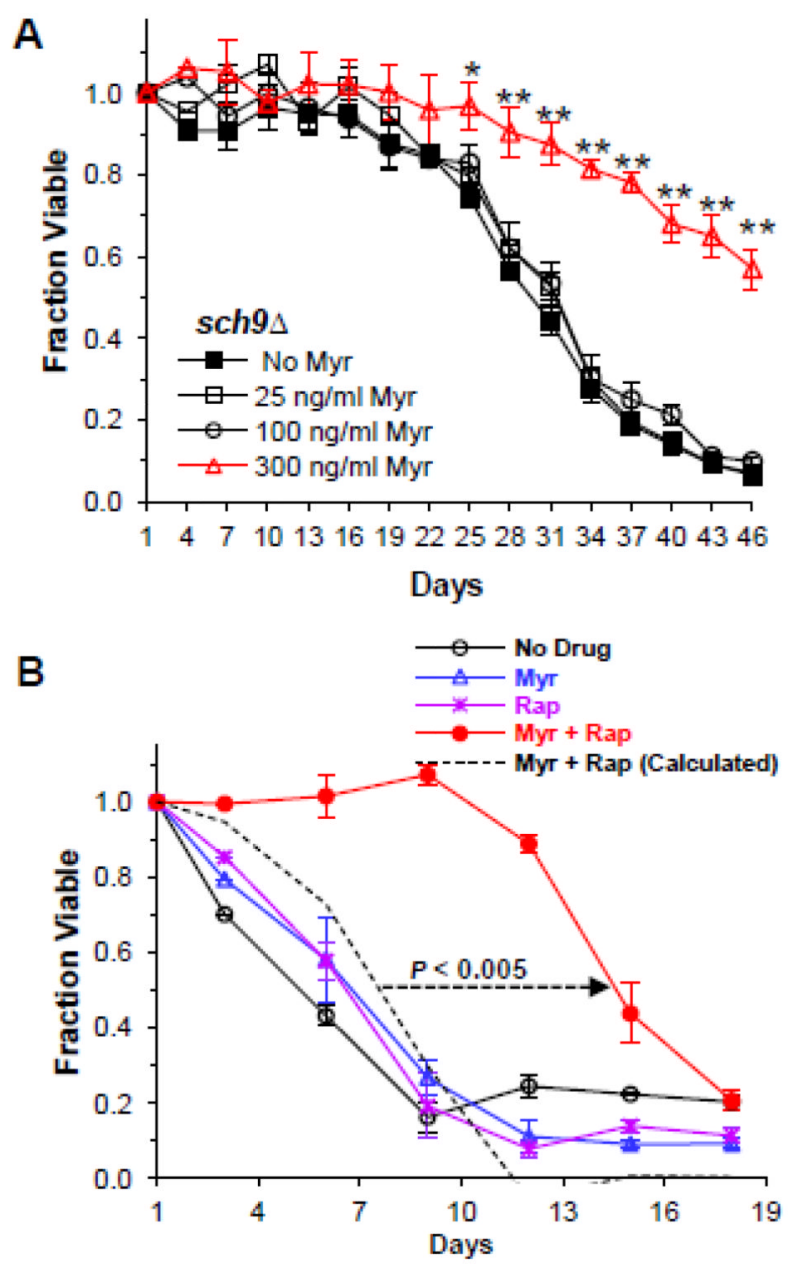

Fig. 3.

Drug treatments increase yeast lifespan. A. The CLS of sch9 $\Delta$ cells (PF102) is enhanced by treating cells with myriocin (Myr). Data represent the mean \pm SEM of survival $(* \mathrm{p}<0.05$, ** $\mathrm{p}<0.01$, No Myr vs $300 \mathrm{ng} / \mathrm{ml}$ Myr). Reproduced with permission [47]. B. Treatment of wild-type (DBY746) yeast cells with a low dose of myriocin plus rapamycin produces a synergistic enhancement in CLS. Cells were incubated with no drug, $45 \mathrm{ng} / \mathrm{ml}$ myriocin (Myr, 112 nM), 450 pg/ml rapamycin (Rap. 0.49 nM), 45 ng/ml Myr plus 450 pg/ml Rap. Data are for the mean \pm SEM of viable cells in triplicate cultures. The dotted straight line with an arrowhead indicates an increase in the CLS of cells treated with both drugs that is greater than the additive effect on CLS of each drug treatment compared to untreated cells (additive effect is indicated by a dashed survival curve). The $p$ value for the lifespan increase is computed using the area under the viability curves. Reproduced with permission [74] 